\title{
Redução da proteína em dietas para tilápias-do-nilo por meio da suplementação de aminoácidos com base no conceito de proteína ideal
}

\author{
José Sérgio Righetti ${ }^{1}$, Wilson Massamitu Furuya ${ }^{2}$, Celso Ivan Conejero ${ }^{3}$, Thêmis Sakaguti \\ Graciano $^{4}$, Luiz Vítor Oliveira Vidal ${ }^{4}$, Mariana Michellato ${ }^{4}$
}

\author{
${ }^{1}$ Mestrando em Zootecnia, UEM. EMATER - Maringá, PR. \\ 2 Departamento de Zootecnia, Universidade Estadual de Maringá- UEM, Maringá, PR. \\ ${ }^{3}$ Departamento de Ciências Morfofisiológicas, UEM, Maringá, PR. \\ ${ }^{4}$ Programa de Pós-graduação em Zootecnia, UEM, Maringá, PR.
}

RESUMO - Este trabalho foi realizado para avaliar os efeitos da redução da proteína da dieta, por meio da suplementação com aminoácidos sintéticos, sobre o desempenho produtivo, a digestibilidade e o diâmetro da fibra muscular de tilápias-do-nilo. Os aminoácidos (lisina, metionina, treonina e arginina) foram suplementados de forma a manter o perfil de aminoácidos da dieta-referência. Foram utilizados 160 peixes com peso vivo médio inicial de $105,7 \pm 2,5 \mathrm{~g}$, distribuídos em 16 tanques ( $1 \mathrm{~m}^{3}$ cada) e alimentados com dietas contendo 26,74;25,82;23,09 ou 22,16\% de proteína digestível durante 110 dias. Não foi observado efeito dos níveis de proteína nas dietas sobre o ganho de peso diário, o índice hepatossomático, a gordura visceral, o rendimento de filé, os teores corporais de umidade, proteína bruta e cinzas, o teor de cinzas no filé, a taxa de sobrevivência e o diâmetro das fibras do músculo dorsal. Com a redução dos níveis de proteína na dieta, foi observada redução linear dos coeficientes de digestibilidade aparente da energia bruta, proteína bruta, extrato etéreo e fósforo das dietas. Houve efeito quadrático dos níveis de proteína sobre a conversão alimentar, a taxa de eficiência proteica, a retenção de nitrogênio, o nitrogênio excretado, a umidade no filé, a gordura corporal e no filé e proteína no filé, de modo que os melhores valores foram estimados com 24,$53 ; 24,25 ; 24,04 ; 25,15 ; 24,67 ; 24,14 ; 24,34$; $25,11 \%$ de proteína digestível, respectivamente. É possível reduzir, de 26,74 para 24,53\%, a proteína digestível em dietas para tilápias-do-nilo na fase de 100 a 500 g.

Palavras-chave: aminoácido, desempenho, digestibilidade, fibra muscular, peixe

\section{Protein reduction in diets for Nile tilapia by amino acids supplementation based on the ideal protein concept}

\begin{abstract}
The objective of this work was to evaluate the effects of reduction of protein in diets for Nile tilapia by supplementation of synthetic amino acids on performance, digestibility and diameter of muscle fiber of Nile tilapias The amino acids (lysine, methionine, threonine and arginine) were supplemented to keep the profile of amino acids in the reference diet. It was used 160 fish with initial live weight of $105.7 \pm 2.5 \mathrm{~g}$, distributed in $16 \operatorname{tanks}\left(1 \mathrm{~m}^{3}\right.$ each tank) fed diets containing $26.74 ; 25.82 ; 23.09$ or $22.16 \%$ of digestible protein for 110 days. It was not observed any effects of protein levels in the diets on daily weight gain, hepatosomatic index, visceral fat, fillet yield, carcass humidity, crude protein and ash, fillet ash, survival rate and on the white muscle fiber diameter. A linear decrease on apparent digestibility coefficients, gross energy, crude protein, ether extract and phosphorus was observed when protein levels in the diet were reduced. There was a quadratic effect on feed conversion ratio, protein efficiency rate, nitrogen retention, nitrogen excretion, fillet humidity, carcass and fillet fat and fillet protein, in which the best-fit responses were estimated with 24.53, 24.25, 24.04, $25.15,24.67,24.14,24.34$ and $25.11 \%$ of digestible protein, respectively. It is possible to reduce the dietary protein level from 26.74 to $24.53 \%$ for Nile tilapia 100 to $500-\mathrm{g}$ phase.
\end{abstract}

Key Words: amino acid, digestibility, fish, muscular fiber, performance

\section{Introdução}

A tilápia-do-nilo é uma das espécies mais importantes para a piscicultura, em razão da rápida taxa de crescimento, da adaptação a diversas condições de criação e das boas características organolépticas da carne, com filés sem espinhas intramusculares em "Y".

Nas últimas décadas, a produção de farinha de peixe tem se mantido estável, em torno de seis milhões de toneladas por ano, o que tem elevado seu custo (FAO, 2009). O farelo 
de soja destaca-se como a fonte proteica mais promissora, pela sua disponibilidade no mercado nacional e pelo elevado valor nutritivo (Kaushik et al., 1995; Furuya et al., 2004a). Entretanto, possui diversos fatores antinutricionais, desbalanço em aminoácidos sulfurados, baixa palatabilidade (Espe et al., 2006), menor valor energético e baixos teores de cálcio e fósforo em relação à farinha de peixe (Furuya et al., 2001), o que torna necessária a suplementação para melhorar o balanceamento de aminoácidos (Furuya et al., 2004b).

Os aminoácidos sintéticos, além de melhorar o perfil quali e quantitativo de aminoácidos e estimular o consumo, são amplamente utilizados quando se deseja reduzir o nível de proteína da ração (Furuya et al., 2004a). Para adequada suplementação de aminoácidos, é necessário o conhecimento das exigências nutricionais e da digestibilidade dos aminoácidos dos alimentos utilizados. Em muitas situações, é necessária a suplementação múltipla de aminoácidos para melhorar a utilização da proteína, de forma a manter contínua a taxa de absorção e evitar desbalanço de aminoácidos (Cowey \& Walton, 1988).

A formulação de dietas com excesso de proteína para atender à exigência de aminoácidos é economicamente inviável, além de causar impactos negativos ao ambiente, uma vez que o nitrogênio é considerado a principal fonte de poluição na piscicultura. A possibilidade de redução da proteína da ração já foi demonstrada em experimentos com carpas (Viola \& Lahav, 1991), tilápias-do-nilo (Furuya et al., 2005; Botaro et al., 2007) e truta arco-íris (Cheng et al., 2003; Gaylord \& Barrows, 2009).

O músculo estriado nos peixes constitui aproximadamente $70 \%$ de seu peso corporal, cujo crescimento ocorre por hipertrofia e/ou hiperplasia (Camargo, 2004). O estudo do desenvolvimento muscular da tilápia tem grande importância quando se procura otimizar a produção de carne.

Apesar da importância econômica da tilápia-do-nilo em diversos países, poucas pesquisas foram realizadas com objetivo de reduzir o conteúdo de proteína por meio da suplementação de aminoácidos em dietas para peixes de tamanho comercial. Assim, realizou-se este trabalho com o objetivo de avaliar os efeitos da redução da proteína da dieta por meio da suplementação de aminoácidos sobre o desempenho produtivo, a digestibilidade aparente e o diâmetro da fibra do músculo branco de tilápias-do-nilo.

\section{Material e Métodos}

O trabalho foi realizado no Laboratório de AquiculturaDBI/UEM no período de dezembro a março de 2008, durante 110 dias. Foram utilizados 160 peixes com peso inicial de $105,7 \pm 2,5 \mathrm{~g}$, distribuídos em 16 tanques ( $1 \mathrm{~m}^{3}$ cada $)$ ligados a um sistema de recirculação de água, em delineamento inteiramente casualizado com quatro dietas, quatro repetições e dez peixes por unidade experimental. Os peixes foram alimentados com dietas contendo 26,74; 25,82; 23,09 ou $22,16 \%$ de proteína digestível, mantendo-se relação energia digestível (kcal):proteína bruta (\%) próxima de 120:1 (Tabela 1).

Cada tanque continha um sistema de aeração composto de pedra porosa acoplada a um soprador, além da aeração proporcionada pelo sistema de recirculação de água (12 L/minuto), realizada por meio de motobomba, de forma a manter o teor de oxigênio dissolvido entre 4 a $6 \mathrm{mg} / \mathrm{L}$. A temperatura da água foi mantida entre 25 e $27^{\circ} \mathrm{C}$. Essas variáveis foram aferidas diariamente, às $8 \mathrm{~h}$ e $17 \mathrm{~h}$ com oxímetro digital portátil.

Os aminoácidos foram suplementados de forma a manter a relação aminoácido essencial/lisina para atender às exigências para tilápias determinadas pelo NRC (1993). Cada dieta foi granulada em moedor de carne, adicionando-se água $\left(52^{\circ} \mathrm{C}\right)$ na proporção de $30 \%$ do peso seco da dieta. Em seguida, os grânulos foram desidratados em estufa de ventilação forçada a $55^{\circ} \mathrm{C}$ e estocados em refrigerador a $5^{\circ} \mathrm{C}$. As dietas foram desintegradas e peneiradas de forma a se obterem grânulos com aproximadamente $4 \mathrm{~mm}$ de diâmetro.

Os peixes foram alimentados manualmente, à vontade, às $8 \mathrm{~h} ; 11 \mathrm{~h} ; 14 \mathrm{~h}$ e $17 \mathrm{~h} 30$. Todos os peixes foram pesados individualmente em balança de precisão $(0,01 \mathrm{~g})$ no início e ao final do experimento, sendo anestesiados com óleo de cravo $(70 \mathrm{mg} / \mathrm{L})$. No início do experimento, foram selecionados os peixes cujo peso estivesse dentro do valor de $20 \%$ do desvio-padrão em relação à média do peso dos peixes de cada unidade experimental. Neste momento, 25 peixes foram armazenados em freezer $\left(-20^{\circ} \mathrm{C}\right)$ para determinação da composição química corporal. No final do experimento, cinco peixes de cada unidade experimental foram filetados, para determinação do rendimento e composição química do filé, e os demais foram eviscerados e moídos, para determinação da composição corporal.

A taxa de eficiência protéica e a retenção de nitrogênio corporal dos peixes foram calculadas de acordo com as expressões descritas por Jauncey \& Ross (1982).

Foram coletadas amostras da porção mediana superficial do músculo dorsal direito de três peixes de cada tanque para mensuração do diâmetro das fibras. Após coleta, as amostras foram aparadas e reduzidas a fragmentos de $1,0 \times 0,5 \mathrm{~cm}$ e cobertas com talco para preservação do tecido (Moline \& Glenner, 1964). Em seguida, foram congeladas com nitrogênio líquido e armazenadas em freezer a $-80^{\circ} \mathrm{C}$ até o processamento. As amostras do 
Tabela 1 - Composição das dietas experimentais

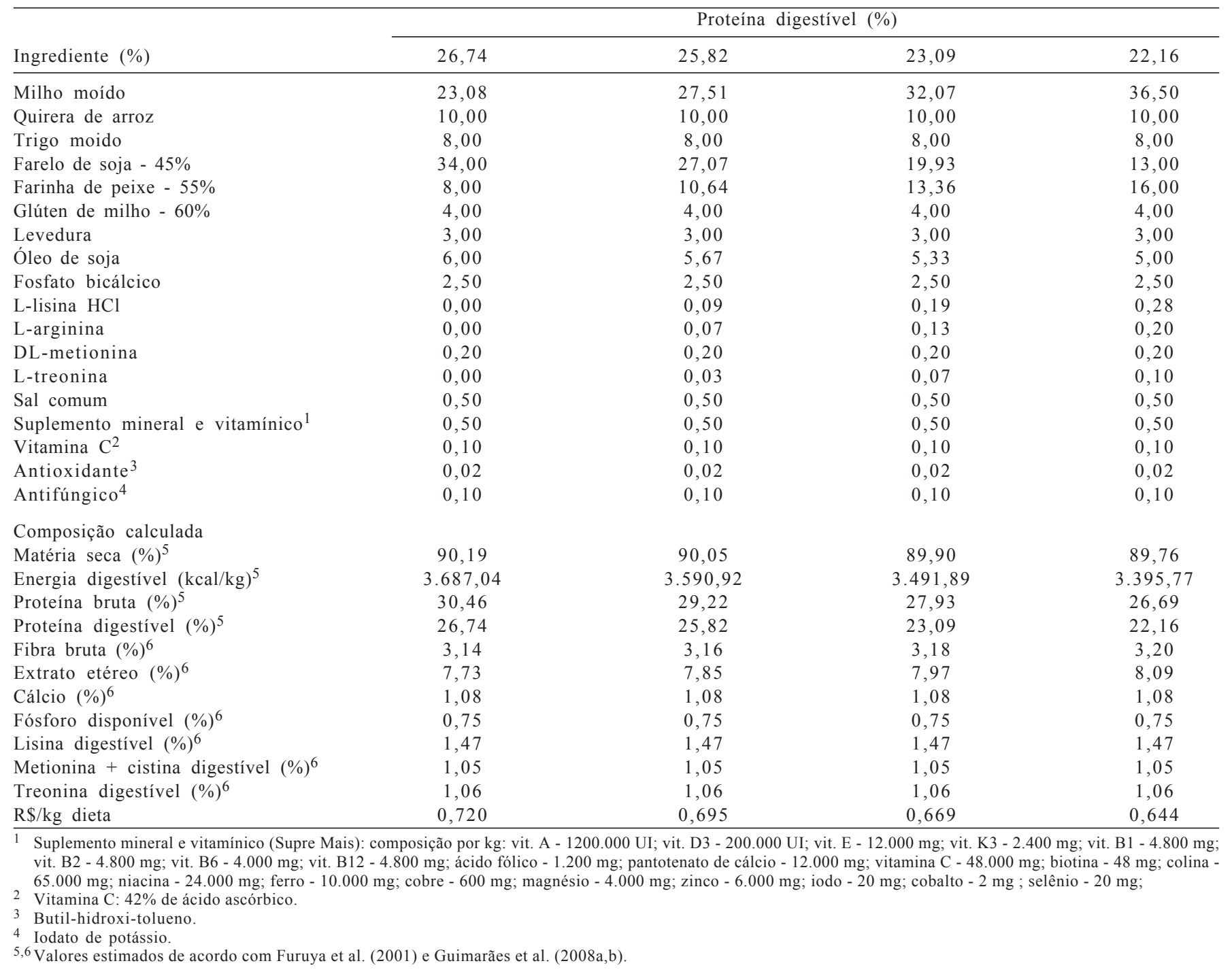

músculo branco foram transferidas para câmara de micrótomo criostato Keichert Jung CM 1800 com temperatura interna de $-20^{\circ} \mathrm{C}$, onde permaneceram por 1 hora. Posteriormente, cada amostra foi fixada em suporte metálico, com adesivo especial (Tissue Tek OCT - Optimal CristalTemperature), efetuando-se várias séries de cortes histológicos com $10 \mu \mathrm{m}$ de espessura (Pullen, 1977).

Os cortes foram submetidos à técnica hematoxilina e eosina (HE) (Lillie, 1954), para avaliação do tecido e mensuração do diâmetro das fibras musculares. A determinação do diâmetro foi obtida pela mensuração do menor diâmetro das fibras (Dubowitz \& Brooke, 1973). Foram capturadas imagens de dez campos microscópicos de cada amostra, com ampliação final de 200X, utilizando-se o programa Analisador de Imagem Computadorizado (Mexia et al., 2006).

Para determinação dos coeficientes de digestibilidade, foram utilizados 21 peixes com peso médio de $258,7 \pm 27,3 \mathrm{~g}$.
Foi determinado o coeficiente de digestibilidade aparente no tempo de cada ração, em duplicata, considerando repetição o pool de fezes dos peixes de cada aquário. Os peixes foram anteriormente adaptados às instalações e ao manejo durante 30 dias.

As tilápias foram mantidas em dois aquários de fibra de vidro, com volume útil de $180 \mathrm{~L}$ para a coleta de fezes, mantidos com aeração constante por meio de pedra porosa acoplada a soprador central, de forma a manter o teor de oxigênio dissolvido em 4 a $6 \mathrm{mg} / \mathrm{L}$. A temperatura da água foi mantida entre 25 e $27^{\circ} \mathrm{C}$ por meio de aquecedor com termostato. Esses parâmetros variáveis foram aferidos diariamente às $8 \mathrm{~h}$ e $17 \mathrm{~h}$, em oxímetro digital portátil para leitura do oxigênio dissolvido e da temperatura. A renovação de água dos aquários de coleta de fezes foi feita diariamente (8h30 e 17h30) utilizando-se a água proveniente de um reservatório de $1.000 \mathrm{~L}$ com água mantida nas mesmas condições dos aquários de digestibilidade. Os peixes foram 
alimentados diariamente das $7 \mathrm{~h}$ às $9 \mathrm{~h}$ e das $13 \mathrm{~h}$ às $17 \mathrm{~h}$, manualmente, até saciedade aparente.

Para determinação dos coeficientes de digestibilidade aparente (CDA), as dietas utilizadas no experimento de desempenho foram moídas e adicionadas de $0,1 \%$ de óxido de crômio III $\left(\mathrm{Cr}_{2} \mathrm{O}_{3}\right)$ como indicador (Pezzato et al., 2002), sendo peletizadas em moinho manual e desidratadas em estufa de ventilação forçada a $55^{\circ} \mathrm{C}$, conforme recomendado por Bremer Neto et al. (2005).

Os coeficientes de digestibilidade da energia e dos nutrientes das dietas foram determinados de acordo com a expressão proposta por Nose (1960):

$$
C D A=100-\left[100 \cdot\left(\frac{\% \mathrm{I}_{\mathrm{d}}}{\% \mathrm{I}_{f}}\right) \cdot\left(\frac{\% N_{f}}{\% N_{d}}\right)\right]
$$

em que: $\mathrm{CDA}=$ coeficiente de digestibilidade aparente (\%); $\% \mathrm{I}_{\mathrm{d}}$ e $\% \mathrm{I}_{\mathrm{f}}=\%$ Indicador na dieta e nas fezes, respectivamente; $\mathrm{e} \% \mathrm{~N}_{\mathrm{f}} \mathrm{e} \% \mathrm{~N}_{\mathrm{d}}=\%$ de nutrientes nas fezes e na dieta, respectivamente.

A retenção de nitrogênio foi calculada de acordo com a expressão:

$$
R n(\%)=\frac{P f . N f-P i . N i}{N c} .100
$$

em que: $\mathrm{Rn}=$ retenção de nitrogênio $(\%) ; \mathrm{Nf}=$ nitrogênio corporal final $(\%) ; \mathrm{Pf}=$ peso final $(\mathrm{g}) ; \mathrm{Ni}=$ nitrogênio corporal inicial $(\%) ; \mathrm{Pi}=$ peso inicial $(\mathrm{g}) ; \mathrm{Nc}=$ nitrogênio consumido $(\mathrm{g})$.

A excreção de nitrogênio fecal foi determinada segundo a expressão:

$$
N e(k g / t G P)=\frac{N C-(N c \cdot C D A n)}{G P} .1000
$$

em que: $\mathrm{Ne}=$ nutriente excretado $(\mathrm{g} / \mathrm{t} \mathrm{GP}) ; \mathrm{Nc}=$ nitrogênio consumido (g); CDAn = coeficiente de digestibilidade aparente do nutriente (\%); GP = ganho de peso (g).

As análises químico-bromatológicas das dietas e corporal dos peixes foram realizadas no Laboratório de Análise de Alimentos do Departamento de Zootecnia da Universidade Estadual de Maringá segundo Silva \& Queiroz (2002).

Os dados foram submetidos à análise de variância e regressão polinomial, utilizando-se o programa SAEG da Universidade Federal de Viçosa (1982).

\section{Resultados e Discussão}

Não foi observado efeito $(\mathrm{P}>0,05)$ dos níveis de proteína digestível nas dietas sobre o ganho de peso diário, o índice hepatosomático, a gordura visceral, o rendimento de filé, os teores corporais de umidade, proteína bruta e cinzas, o conteúdo de cinzas no filé, a taxa de sobrevivência e o diâmetro das fibras brancas do músculo dorsal.
Foram obtidos valores médios de 71,21 $\pm 5,71 ; 69,05 \pm 3,74$; $66,15 \pm 3,15$ e $66,40 \pm 3,93 \mu \mathrm{m}$ de diâmetro das fibras musculares para os peixes alimentados com dietas contendo 26,$74 ; 25,82 ; 23,09$ e $22,16 \%$ de proteína digestível, respectivamente.

O crescimento do tecido muscular ocorre por dois processos: aumento do diâmetro da fibra (hipertrofia) e aumento do número de fibras existentes (hiperplasia), por meio da atividade dos mioblastos indiferenciados (células satélites), que também estão envolvidos nos processos de reparação muscular em casos de lesão (Camargo, 2004).

A diferenciação muscular origina a maior massa de tecido do organismo, correspondendo a aproximadamente $50 \%$ do peso corporal na maioria das espécies animais. Considerando que os maiores componentes do músculo são as fibras musculares, deduz-se que a taxa de crescimento pós-natal de um músculo é determinada pelo número de fibras musculares e pela taxa de crescimento individual das fibras (Scheuermann, 2004).

A mensuração da área/diâmetro das fibras constitui um parâmetro importante na avaliação do crescimento muscular e também para verificar qual tipo de fibra é mais susceptível ao crescimento. Smith \& Fletcher (1988) verificaram em aves que as fibras brancas têm taxas de crescimento superiores às das fibras vermelhas. Mais recentemente, Aguiar et al. (2005) determinaram que o diâmetro das fibras brancas de tilápias-do-nilo é superior ao das fibras vermelhas e intermediárias.

Segundo Johnston et al. (1975), o crescimento muscular está associado ao aumento do diâmetro das fibras e influenciado pelo nível nutricional da dieta. Em peixes adultos, espera-se que a hipertrofia das fibras promova aumento da massa muscular, aumento do peso do filé e produção de carne.

Aguiar et al. (2005) destacaram a importância do adequado nível de lisina na dieta sobre o crescimento das fibras brancas de larvas de tilápia-do-nilo. A lisina, juntamente com a metionina e treonina, são aminoácidos importantes para o crescimento dos peixes, particularmente no desenvolvimento das fibras musculares, principalmente durante o período de crescimento hipertrófico, objetivando o aumento na produção de filés.

A suplementação de arginina é necessária para atender sua exigência para manutenção e produção e evitar antagonismos com a lisina, assim, é importante uma relação arginina:lisina próxima de 1 em dietas para tilápia-do-nilo (Furuya et al., 2004b).

A hiperplasia é mais acentuada nas fases larval e de alevino, mas posteriormente predomina o crescimento hipertrófico das fibras. Aguiar etal.(2005)e Furuya etal. (2005) 
verificaram diâmetros próximos de 22 e $30 \mu \mathrm{m}$ para tilápias de 0,48 e $125 \mathrm{~g}$, respectivamente.

Para os diâmetros das fibras do músculo dorsal dos peixes, foi observado acentuado grau de hipertrofia em relação aos peixes mais jovens: as de menor diâmetro foram mais arredondadas, enquanto as de maior diâmetro apresentaram aspecto mais hipertrófico e tiveram contorno poligonal. O tecido conjuntivo que envolve cada uma das fibras apresentou-se pouco desenvolvido, conferindo aspecto compacto às mesmas.

Neste trabalho, confirmou-se a possibilidade de redução da proteína digestível, de 26,74 para $24,53 \%$, em dietas para tilápias-do-nilo, uma vez que a suplementação de aminoácidos em dietas com menores teores de proteína atendeu às exigências para crescimento muscular, possibilitando a manutenção do crescimento em peso, composição de proteína corporal e diâmetro das fibras dos peixes. Possivelmente, é necessária a suplementação de aminoácidos essenciais e não-essenciais para maior redução do nível de proteína, o que pode ser inviável do ponto de vista econômico, em função do elevado custo dos aminoácidos.

Os níveis de proteína tiveram efeito quadrático $(\mathrm{P}<0,05)$ sobre a conversão alimentar (Figura 1), a taxa de eficiência proteica, a retenção de nitrogênio e a excreção de nitrogênio, de modo que os melhores valores foram estimados com 24,$53 ; 24,25 ; 24,04$ e $25,15 \%$ de proteína digestível, respectivamente (Tabela 2 ).

A possibilidade de redução da proteína bruta da dieta, de 30 para $25 \%$, com a suplementação de lisina já foi demonstrada por Viola \& Lahav (1991) em experimento com carpas. Para tilápias-do-nilo de 4 a 120 g, Furuya et al. (2005) descreveram a possibilidade de redução da proteína digestível da dieta de 33,7 para 30,89\% com a suplementação de metionina, lisina e treonina, enquanto Botaro et al. (2007) relataram que a proteína digestível em dietas para tilápias- do-nilo de 35 a 270 g pode ser reduzida de 29,12 para $26,2 \%$ com a suplementação de metionina, lisina e treonina.

Cheng et al. (2003) observaram possibilidade de redução do teor de proteína, de 42 para $37 \%$, em dietas para truta arco-íris com a suplementação de lisina, metionina, treonina e triptofano. Com a mesma espécie, Gaylord \& Barrows (2009) demonstraram que é possível reduzir, de 45 para 35\%, a proteína bruta da dieta por meio da suplementação de lisina, metionina, treonina, glicina e taurina, sem prejuízos sobre o ganho de peso, a conversão alimentar, a utilização da proteína da dieta e o rendimento de filé. Esses autores também observaram menor valor de índice hepatossomático dos peixes alimentados com dietas contendo $35 \%$ de proteína bruta, fato não verificado neste trabalho, em que o peso do fígado foi relacionado ao peso corporal dos peixes ao final do experimento e não aos níveis de proteína das dietas.

A eficiência de utilização dos aminoácidos sintéticos tem sido controversa em peixes, principalmente em dietas para bagre-do-canal, como demonstrado por Li \& Robinson(1998),

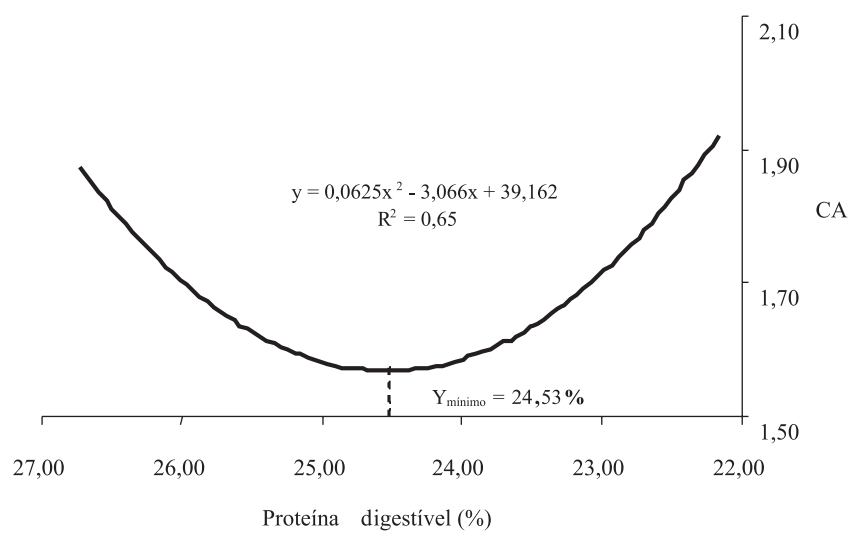

Figura 1 - Conversão alimentar de tilápias-do-nilo alimentadas com dietas com nível de proteína reduzido suplementadas com aminoácidos.

Tabela 2 - Valores médios de desempenho de tilápias-do-nilo alimentadas com dietas com nível de proteína digestível reduzido e suplementadas com aminoácidos

\begin{tabular}{|c|c|c|c|c|c|}
\hline & \multicolumn{5}{|c|}{ Proteína digestível (\%) } \\
\hline & 26,74 & 25,82 & 23,09 & 22,16 & $\mathrm{CV}$ \\
\hline Peso inicial $(\mathrm{g})$ & 107,13 & 104,93 & 103,95 & 104,73 & 2,45 \\
\hline Peso final $(g)$ & 456,98 & 453,82 & 493,05 & 482,57 & 6,76 \\
\hline Ganho de peso $(\mathrm{g})$ & 351,13 & 348,89 & 389,12 & 377,84 & 7,96 \\
\hline Conversão alimentar ${ }^{1}$ & 1,90 & 1,63 & 1,74 & 1,90 & 4,79 \\
\hline Taxa de eficiência proteica ${ }^{1}$ & 1,92 & 2,41 & 2,31 & 2,21 & 4,33 \\
\hline Retenção de nitrogênio $(\%)^{1}$ & 36,65 & 38,98 & 38,17 & 37,65 & 3,27 \\
\hline Nitrogênio excretado (g/t ganho de peso $)^{1}$ & 9,90 & 6,12 & 11,47 & 12,33 & 25,43 \\
\hline Rendimento de filé $(\%)$ & 31,15 & 29,65 & 29,65 & 29,71 & 2,15 \\
\hline Índice hepatossomático (\%) & 2,12 & 2,36 & 3,21 & 2,32 & 12,08 \\
\hline Gordura visceral (\%) & 1,27 & 1,54 & 1,57 & 1,49 & 14,79 \\
\hline
\end{tabular}

$\mathrm{CV}=$ coeficiente de variação.

${ }^{1}$ Efeito quadrático: $(\mathrm{P}<0,05)$ : conversão alimentar $\left(\mathrm{Y}=39,1623-3,0655 \mathrm{X}+0,06252 \mathrm{X}^{2} ; \mathrm{R}^{2}=0,65\right)$; taxa eficiência proteica $\left(\mathrm{Y}=-49,8154+4,3179 \mathrm{X}-0,0890 \mathrm{X}^{2}\right.$; $\left.\mathrm{R}^{2}=0,68\right)$; retenção de nitrogênio $\left(\mathrm{Y}=-174,4000+17,8400 \mathrm{X}-0,3710 \mathrm{X}^{2} ; \mathrm{R}^{2}=0,69\right)$; nitrogênio excretado $\left(\mathrm{Y}=-437,200-34,2400 \mathrm{X}+0,6810 \mathrm{X}^{2} ; \mathrm{R}^{2}=0,83\right)$. 
que não observaram efeitos positivos da suplementação de lisina e metionina sobre o desempenho da espécie em estudo objetivando reduzir o teor de proteína da dieta. Destaca-se que as diferenças relacionadas aos níveis de energia, proteína e aminoácidos, bem como no manejo alimentar dos peixes, podem influenciar os resultados obtidos.

Estimou-se que a menor excreção de nitrogênio seria obtida com $25,25 \%$ de proteína digestível, tendo em vista o melhor balanceamento de aminoácidos da dieta. No entanto, a redução do nível de proteína abaixo do valor citado não permitiu adequada utilização da fração nitrogenada, o que pode ter sido consequência da elevada inclusão de aminoácidos sintéticos, que são rapidamente absorvidos, em comparação a aminoácidos ligados à proteína dos alimentos (Yamada et al., 1981; Cowey \& Walton, 1988), com a elevação súbita dos aminoácidos sintéticos nos níveis plasmáticos (Schumacher et al., 1997), e pelas perdas por catabolismo (Plakas \& Katayama, 1981; Murai et al., 1985). Além disso, com a redução de proteína, pode ter ocorrido deficiência de outro aminoácido, que não era limitante nos níveis mais elevados de proteína e que não foi suplementado nas dietas.

Outro fator que pode influenciar a utilização dos aminoácidos sintéticos pelos peixes é a alta taxa de lixiviação dos aminoácidos sintéticos em dietas para peixes (Zarate \& Lovell, 1997). Neste trabalho, adotou-se a frequência de arraçoamento de quatro vezes por dia para evitar sobras e perdas de aminoácidos para o meio aquático.

Pesquisadores têm demonstrado a importância da utilização de aminoácidos sintéticos em dietas para peixes quando utilizadas fontes alternativas de proteína em substituição à farinha de peixe, principalmente quando se deseja reduzir o nível de proteína da dieta. Para a redução do nível de proteína, além da metionina e lisina, há necessidade de avaliar a presença dos demais aminoácidos de forma quantitativa e qualitativa, principalmente para evitar a presença de aminoácidos limitantes e antagonismos entre os mesmos. É necessário verificar também os níveis dos aminoácidos não-essenciais (Cowey, 1994) considerando as elevadas perdas de nitrogênio endógeno em relação aos animais terrestres (Abboudi et al., 2009).

Não foi observado efeito $(\mathrm{P}>0,05)$ dos níveis de proteína da dieta sobre os teores de umidade, proteína, e cinzas corporais e de cinzas no filé. A redução nos níveis de proteína da dieta teve efeito quadrático (Tabela 3 ) sobre os teores de gordura corporal, umidade, proteína (Figura 2) e gordura nos filés.

Apesar da importância da composição química corporal, destaca-se a dificuldade de preparo da amostra para análises laboratoriais, pela presença de ossos, escamas e nadadeira, que dificultam a moagem dos peixes e obtenção de amostra homogênea, o que não ocorre com amostras de filés. Assim, presupondo a relação positiva entre a composição química corporal e do filé, parecem ser mais adequadas as inferências dos efeitos da redução da proteína digestível da dieta sobre a composição química dos filés.

A composição em umidade dos filés dos peixes foi inversamente relacionada aos teores de proteína e gordura nos filés, de modo que os menores teores de umidade foram observados nos maiores teores de proteína e gordura nos filés. O adequado nível de proteína e o balanceamento de aminoácidos influenciaram a deposição de proteína nos filés, mas não acarretou redução nos níveis de gordura, principalmente pela suplementação de lisina, como observado por Zhou et al. (2007) em experimento com juvenis de cobia (Rachycentron canadum).

Tabela 3 - Composição química corporal e do filé de tilápias-donilo alimentadas com dietas com nível de proteína digestível reduzido suplementadas com aminoácidos

\begin{tabular}{|c|c|c|c|c|c|}
\hline & \multicolumn{4}{|c|}{ Proteína digestível (\%) } & \multirow[b]{2}{*}{$\mathrm{CV}$} \\
\hline & 26,74 & 25,82 & 23,09 & 22,16 & \\
\hline & \multicolumn{4}{|c|}{ Composição química corporal (\%) } & \\
\hline Umidade & 68,75 & 66,20 & 65,59 & 67,39 & 2,2 \\
\hline Proteína bruta & 17,12 & 16,36 & 16,16 & 16,37 & 2,7 \\
\hline Extrato etéreo ${ }^{1}$ & 6,88 & 9,48 & 9,73 & 8,78 & 7,0 \\
\hline \multirow[t]{2}{*}{ Cinzas } & 5,25 & 5,49 & 5,33 & 5,05 & 15,6 \\
\hline & \multicolumn{4}{|c|}{ Composição química do filé (\%) } & \\
\hline Umidade $^{1}$ & 74,56 & 73,37 & 74,00 & 75,11 & 0,62 \\
\hline Proteína bruta ${ }^{1}$ & 21,40 & 21,85 & 21,18 & 20,52 & 1,4 \\
\hline Extrato etéreo ${ }^{1}$ & 1,88 & 2,32 & 2,39 & 2,01 & 9,62 \\
\hline Cinzas & 1,38 & 1,45 & 1,38 & 1,37 & 3,3 \\
\hline
\end{tabular}

$\mathrm{CV}=$ coeficiente de variação

${ }^{1}$ Efeito quadrático $(\mathrm{P}<0,05)$ : gordura corporal $(\mathrm{Y}=-295,0538+25,297 \mathrm{X}$ $\left.0,5247 \mathrm{X}^{2} ; \mathrm{R}^{2}=0,78\right)$; umidade do filé $\left(\mathrm{Y}=279,1850-16,7108 \mathrm{X}+0,3387 \mathrm{X}^{2}\right.$ $\left.\mathrm{R}^{2}=0,73\right)$; proteína no filé $\left(\mathrm{Y}=-80,8457+8,1898 \mathrm{X}-0,1632 \mathrm{X}^{2} ; \mathrm{R}^{2}=0,77\right)$ gordura no filé $\left(\mathrm{Y}=-69,5513+5,9283 \mathrm{X}-0,1218 \mathrm{X}^{2} ; \mathrm{R}^{2}=0,61\right)$.

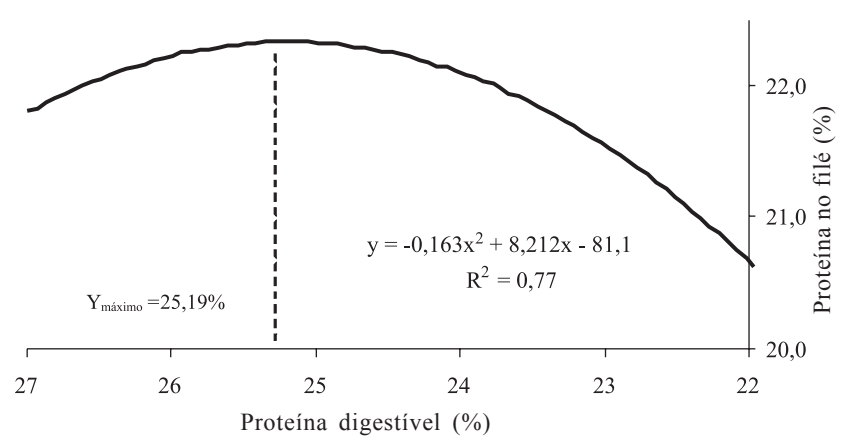

Figura 2 - Valores médios de proteína no filé de tilápias-do-nilo alimentadas com dietas com nível reduzido de proteína digestível suplementadas com aminoácidos. 
Com a redução dos níveis de proteína na dieta, foi observada redução linear nos coeficientes de digestibilidade aparente da energia bruta, proteína bruta, extrato etéreo e fósforo das dietas (Tabela 4).

A redução nos coeficientes de digestibilidade da energia e dos nutrientes da dieta com o menor teor de proteína provavelmente está relacionada à maior inclusão de farinha de peixe, em função do maior valor de cinzas, que reduz a digestibilidade da energia e nutrientes, piorando a conversão alimentar. Para tilápias-do-nilo, valores inferiores de coeficientes de digestibilidade da matéria seca e proteína bruta da farinha de peixe em relação aos obtidos com o farelo de soja foram encontrados por Furuya et al. (2001), Pezzato et al. (2002) e Guimarães et al. (2008).

As tilápias destacam-se pela elevada digestibilidade da energia e nutrientes dos alimentos convencionais e alternativos de origem vegetal (Fagbenro, 1998; Pezzato et al., 2002), principalmente pela utilização dos carboidratos como fonte de energia (Degani \& Revach, 1991), o que não ocorre na mesma proporção em peixes carnívoros (NRC, 1993). De acordo com (Kubarik, 1997), as tilápias possuem adaptações morfológicas e fisiológicas que permitem a utilização mais eficiente dos alimentos de origem vegetal (Hanley, 1987; Guimarães et al., 2008a,b).

Para adequada suplementação de aminoácidos, é necessário o conhecimento das exigências e da digestibilidade dos aminoácidos dos alimentos utilizados. Nos últimos anos, com a determinação dos coeficientes de digestibilidade aparente da energia e proteína dos alimentos convencionais e alternativos (Furuya et al., 2001; Pezzato et al., 2002) e valores de proteína e aminoácidos digestíveis dos alimentos (Furuya et al., 2001; Pezzato et al., 2002; Guimarães et al., 2008a,b) para a tilápia-do-nilo, há possibilidade de elaboração de dietas mais precisas, que atendam as exigências dos peixes e que resultem em menor impacto ambiental.

Tabela 4 - Coeficientes de digestibilidade aparente da energia e dos nutrientes das dietas contendo diferentes níveis de proteína digestível

\begin{tabular}{lrrrrr}
\hline & \multicolumn{5}{c}{ Proteína digestível (\%) } \\
\cline { 2 - 6 } & 26,74 & 25,82 & 23,09 & 22,16 & $\mathrm{CV}$ \\
\hline Energia bruta $(\%)^{1}$ & 79,22 & 78,79 & 76,65 & 74,14 & 3,01 \\
Proteína bruta $(\%)^{1}$ & 88,15 & 90,76 & 83,44 & 83,04 & 4,34 \\
Extrato etéreo $(\%)^{1}$ & 91,78 & 92,11 & 89,96 & 88,66 & 1,78 \\
Fósforo (\%) & 61,79 & 60,04 & 58,33 & 40,73 & 17,68 \\
\hline
\end{tabular}

$\mathrm{CV}=$ coeficiente de variação.

${ }^{1}$ Efeito linear: $(\mathrm{P}<0,05)$ : energia bruta $\left(\mathrm{Y}=52,1587+1,0241 \mathrm{X} ; \mathrm{R}^{2}=0,66\right)$; proteína bruta $\left(\mathrm{Y}=49,0439+1,5255 \mathrm{X} ; \mathrm{R}^{2}=0,77\right)$; extrato etéreo $(\mathrm{Y}=73,3019+$ $\left.0,7086 \mathrm{X} ; \mathrm{R}^{2}=0,84\right)$; fósforo $\left(\mathrm{Y}=-31,8174+3,5598 \mathrm{X} ; \mathrm{R}^{2}=0,58\right)$

\section{Conclusões}

É possível reduzir de 26,74 para $24,53 \%$ a proteína digestível em dietas para a tilápia-do-nilo na fase de 100 a $500 \mathrm{~g}$.

\section{Referências}

ABBOUDI, T.; MAMBRINI, M.; LARONDELLE, Y. et al. The effect of dispensabel amino acids on nitrogen and amino acid losses in Atlantic salmon (Salmo salar) fry fed a protein-free diet. Aquaculture, v.289, p.327-333, 2009.

AGUIAR, D.H.; BARROS, M.M.; PADOVANI, C.R. et al. Growth characteristics of skeletal muscle tissue in Oreochromis niloticus larvae fed on a lysine supplemented diet. Journal of Fish Biology, v.67, p.1287-1298, 2005.

BOTARO, D.; FURUYA, W.M.; SILVA, L.C.R. et al. Redução da proteína da dieta com base no conceito de proteína ideal para tilápias-do-nilo (Oreochromis niloticus) criadas em tanquesrede. Revista Brasileira de Zootecnia, v.36, n.3, p.517-525, 2007.

BREMER-NETO, H.; GRANER, C.A.F.; PEZZATO, L.E. et al The spectrophotometric method on the routine of 1,5dipenylcarbazide was adjusted on chromium determination in feces, aftes its utilization as a biological marker as chromium (III) oxide. Ciência Rural, v.35, p.691-697, 2005.

CAMARGO, A.A.C.; DAL PAI SILVA, M.; PELLIZZON, C.H. et al. Aspectos morfológicos da regeneração muscular na tilápiado-nilo (Oreochromis niloticus). International Journal of Morphology, v.22, n.1, 2004.

CHENG, Z.J.; HARDY, R.W.; USRY, J.L. Plant protein ingredients with lysine supplementation reduce dietary protein level in rainbow trout (Oncorhynchus mykiss) diets, and reduce ammonia nitrogen and soluble phosphorus excretion. Aquaculture, v.218, p.553-565, 2003.

COWEY, C.B. Amino acid requirements of fish: a critical appraisal of present values. Aquaculture, v.123, p.1-11, 1994.

COWEY, C.B.; WALTON, M.J. Studies on the uptake of $\left({ }^{14} \mathrm{C}\right)$ amino acids derived from both dietary $\left({ }^{14} \mathrm{C}\right)$ protein and dietary $\left({ }^{14} \mathrm{C}\right)$ amino acids by rainbow trout, Salmo gairdneri Rich. Journal of Fish Biology, v.33, p.293-305, 1988.

DEGANI, G.; REVACH, A. Digestive capabilities of three commensal fish species: carp, Cyprinus carpio L., tilapia, Oreochromis aureus x O. niloticus, and African catfish, Clarias gariepinus (Burchell, 1882). Aquaculture and Fisheries Management, v.22, p.397-403, 1991.

DUBOWITZ, V.; BROOKE, M.H. Muscle biopsy: a modern approach. London: Sunders, 1973. 220p.

ESPE, M.; LEMME, A.; PETRI, A. et al. Can Atlantic salmon grow on diets devoid of fish meal? Aquaculture, v.255, p.255-262, 2006.

FAGBENRO, O.A.; BALOGUN, A.M.; FASAKIN, E.A. et al. Dietary lysine requirement of the African catfish, Clarias gariepinus. Journal of Applied Aquaculture, v.8, p.71-77, 1998.

FOOD AND AGRICULTURE ORGANIZATION - FAO. The state of world fisheries and aquaculture 2008. Rome: 2009. 196p.

FURUYA, W.M.; PEZZATO, L.E.; MIRANDA, E.C. et al. Coeficientes de digestibilidade e valores de aminoácidos digestíveis de alguns ingredientes pela tilápia do nilo (Oreochromis niloticus). Revista Brasileira de Zootecnia, v.30, n.4, p.1125-1131, 2001a.

FURUYA, W.M.; HAYASHI, C.; FURUYA, V.R.B. Exigência de metionina + cistina total e digestível para alevinos revertidos de tilápia-do-nilo, Oreochromis niloticus (L.), baseadas no conceito de proteína ideal. Acta Scientiarum, v.23, p.885-889, $2001 \mathrm{~b}$. 
FURUYA, W.M.; PEZZATO, L.E.; BARROS, M.M. et al. Use of ideal protein concept for precision formulation of amino acid levels in fish-meal-free diets for juvenile Nile tilapia (Oreochromis niloticus L.). Aquaculture Research, v.3, p.1110-1116, 2004a.

FURUYA, W.M.; BOTARO, D.; NEVES, P.R. Exigência de lisina pela tilápia-do-nilo (Oreochromis niloticus) na fase de terminação. Ciência Rural, v.34, n.6, p.1933-1937, 2004b.

FURUYA, W.M.; BOTARO, D.; MACEDO, R.M.G. et al. Aplicação do conceito de proteína ideal para redução dos níveis de proteína em dietas para tilápia-do-nilo (Oreochromis niloticus). Revista Brasileira de Zootecnia, v.34, p.1433-1441, 2005.

GAYLOR, T.G.; BARROWS, F.T. Multiple amino acid supplementations to reduce dietary protein in plant-based rainbow trout, Oncorhynchus mykiss, feeds. Aquaculture, v.287, p. 180-184, 2009.

GUIMARÃES, T.G.; PEZZATO, L.E.; BARROS, M.M. et al. Nutrient digestibility of cereal grain products and by-products in extruded diets for Nile tilapia. Journal of World Aquaculture Society, v.39, n.6, p.781-789, 2008a

GUIMARÃES, T.G.; PEZZATO, L.E.; BARROS, M.M. Amino acid availability and protein digestibility of several protein sources for Nile tilapia. Aquaculture Nutrition, v.14, p.396-404, 2008b.

HANLEY, F. The digestibility of foodstuffs in the effects of feeding selectivity on digestibility determination in tilapia, Oreochromis niloticus (L.). Aquaculture, v.6, p.163-179, 1987.

JAUNCEY, K.; ROSS, B. A guide to tilapia feed and feeding. Scotland: University of Stirling, 1982. 111p.

JOHNSTON, M.D.; STWART, D.F.; MOODY, W.G. et al. Effect and time of feed on size and distribution of bred muscle fiber types. Journal of Animal Science, v.40, p.613-620, 1975.

KAUSHIK, S.J.; CRAVEDI, J.P.; LALLES, J.P. Partial or total replacement of fish meal by soybean protein on growth, protein utilization, potential estrogenic or antigenic effects, cholesterolemia and flesh quality in rainbow trout (Onchorhyncus mykiss). Aquaculture, v.133, p.257-274, 1995.

KUBARIK, J. Tilapia on highly flexible diets. Feed International, v. 6, p.16-18, 1997.

LI, M.H.; ROBINSON, E.H. Effects of supplemental Lysine and Methionine in low protein diets on weight gain and body composition of young channel catfish (Ictalurus punctatus). Aquaculture, v.163, p.297-307, 1998.

LILLIE, R.D. Histopathologc technic and pratical histochemistry. 2.ed. New York: Blakiston, 1954. 501p.

MEXIA, A.A.; MACEDO, F.A.F.; MACEDO, R.M.G. et al. Desempenho e características das fibras musculares esqueléticas de cordeiros nascidos de ovelhas que receberam suplementação alimentar em diferentes períodos da gestação. Revista Brasileira de Zootecnia, v.35, n.4, p.1780-1787, 2006.

MOLINE, S.W.; GLENNER, G.G. Ultrarapid tissue freezing in liquid nitrogen. Journal Histochemistry and Cytochemistry, v.12, n.10, p.777-783, 1964
MURAI, T.; AKIYAMA, T.; WATANABE, T. et al. Effects of dietary protein and lipids levels on performance and carcass composition of fingerlings carp (Cyprinus carpo). Bulletin of the Japanese Society of Scientific Fisheries, v.54, p.605-608, 1985.

NATIONAL RESEARCH COUNCIL - NRC. Nutrient requirements of warmwater fishes and shellfishes. Washington, D.C.: National Academy Press, 1993. 102p.

NOSE, T. On the digestion of food protein by gold-fish (Carassius auratus) L.) and rainbow trout (Salmo irideus G.). Bulletin Freshwater Fish Research Laboratory, v.10, p.11-22, 1960.

PEZZATO, L.E.; MIRANDA, E.C.; BARROS, M.M. et al Digestibilidade aparente de ingredientes pela tilápia-do-nilo (Oreochromis niloticus). Revista Brasileira de Zootecnia, v. 31, n.4, p.1595-1604, 2002

PLAKAS, S.M.; KATAYAMA, T. Apparent digestibilities of amino acids from three regions of the gastrointestinal tract of carp (Cyprinus carpo) after ingestion of a protein and corresponding free amino acid diet. Aquaculture, v.24, p.309-314, 1981.

PULLEN, A.H. The distribution and relative sized of fibre types in the extensor digitorum longus and soleus muscles of the adult rat. Journal of Anatomy, v.123, n.1, p.467-86, 1977.

SAEG - UNIVERSIDADE FEDERAL DE VIÇOSA - UFV. SAEG Sistema de análises estatísticas e genéticas. Viçosa, MG: UFV, 1982. 52p.

SCHEUERMANN, G.N. Alteração na quantidade e qualidade da carne de aves através da manipulação das fibras musculares. In: CONFERENCIA APINCO DE CIENCIA E TECNOLOGIA AVICOLAS, 2004, Santos. Anais... Campinas: FACTA, 2004, v.2. p.165-178.

SCHUHMACHER, A.; WAX, C.; GROPP, J.M. Plasma amino acids in rainbow trout (Oncorhynchus mykiss) fed intact protein or a crystalline amino acid diet. Aquaculture, v.151, p.15-28, 1997.

SILVA, D.J.; QUEIROZ, A.C. Análise de alimentos (métodos químicos e biológicos). 3.ed. Viçosa, MG: Universidade Federal de Viçosa, 2002. 235p

SMITH, D.P.; FLETCHER, D.L. Chicken breast muscle fiber type and diameter as influenced by age and intramuscular location. Poultry Science, v.67, p.908-913, 1988.

VIOLA, S.; LAHAV, E. Effects of lysine supplementation in practical carp feeds on total protein sparing and reduction of pollution. The Israeli Journal of Aquaculture, v.43, p.112-118, 1991.

YAMADA, S.; SIMPSOM, K.; TANAKA, Y. et al. Plasma amino acid changes in rainbow trout force-fed casein and corresponding amino acid mixture. Bulletin of Japanese Society of Scientific Fisheries, v.47, p.1035-1040, 1981.

ZARATE, D.D.; LOVELL, R.T. Free lysine (L-lysine.HCl) is utilized for growth less efficiently than protein-bound lysine (soybean meal) in practical diets by young channel catfish (Ictalurus punctatus). Aquaculture, v.159, p.87-100, 1997.

ZHOU, Q.C.; WU, Z.H.; CHI, S.Y. et al. Dietary lysine requirement of juvenile cobia (Rachycentron Canadum). Aquaculture, v.273, p.634-640, 2007 